\title{
The Role of Universities in Enhancing Regional Competitiveness of Jilin Province
}

\author{
Xiuping Dong \\ School of Marxism, Changchun University of Science and Technology \\ Changchun 130022, China \\ E-mail: windyxiu@sina.com \\ Meng Tang \\ School of Law, Changchun University of Science and Technology \\ Changchun 130022, China
}

Received: June 24, 2011

Accepted: July 14, 2011

Published: October 1, 2011

doi:10.5539/ass.v7n10p177

URL: http://dx.doi.org/10.5539/ass.v7n10p177

\begin{abstract}
With development of the times, relationship between higher education and social development becomes increasingly closer, and universities and the cities or regions where they are located play an irreplaceable role in promoting development of the cities or the regions. Thus, it is an important approach to depend on university resources to realize scientific development depending on university resources to enhance provincial competitiveness. As advanced culture, university culture directs and pushes forward cultural development and the scientific research and innovation work of universities is an important source to strengthen provincial scientific competitiveness and innovativeness.
\end{abstract}

Keywords: Universities, Regional competitiveness of Jilin Province, Role

Regional competitiveness mainly refers to the international competitiveness of economy in a country or a region in the economic globalization environment, namely, the ability of an economic region to produce more wealth than the competitor (other regions of the same kind) and occupy a domestic and foreign market with more shares by attracting and effectively distributing resources within the global sphere so as to realize sustainable increase of regional economy. The World Economic Forum (WEF) and International Institute for Management Development (IMD) pointed out in the international competitiveness evaluation system that was established in 1980, the international competitiveness was a quantified concept, and among the eight major elements, scientific competitiveness and competitiveness of the populace's cultivation were the core competitiveness. There are 22 out of the 44 indexes in the competitiveness of populace's competitiveness and 19 out of the 26 indexes in the scientific competitiveness that are related with education, especially higher education. Furthermore, regional innovation becomes the major motive for regional economic sustainable development and knowledge resource is endowed with new connotation in regional innovation. Regional innovation clamors for double improvement of knowledge resource both in terms of quality and in terms of quantity and requires the higher education which is the important place of origin for development of high intelligence and innovation to assume more important responsibilities in the process of regional economic development. In other words, the "populace's cultivation and science and technology" with the source of higher education are the core elements to enhance regional competitiveness.

In the past thirty years or so since the reform and opening up in China, higher education has undergone the developmental states of setting things right, intensifying the reform, great-leap-forward development and construction of connotation, etc, and has achieved notable achievements, with strong strength and solid developmental foundation. In such an optimistic situation, some economically developed provinces have taken the lead in the strategic target of establishing powerful education or higher education as early as several years ago. The Party's Seventeenth Congress proposed, "We have to give priority to development of education and construct a country with powerful human resources". In order to carry out the spirit of the Party's Seventeenth 
Congress, some provinces with good foundation of higher education have also put forward in succession the developmental goal of "setting up a province with strong higher education", and a province with strong higher education has become the behaviors of a government and the common sense of the public.

Education is the footstone for a nation to revive, whereas bears the heavy burden of fostering all sorts of high quality talents, creating high level scientific research achievements and offering first-class social service and occupies an important strategic position in the process of setting up a strong country with human resources. Higher education with rational structure, diversified levels, first-class quality and strong ability to transfer knowledge to productivity is not only the important guarantee to set up a strong country with human resources, but also the basic strength to promote social development.

Universities are the important base for knowledge innovation and technical innovation of a nation, the radiation source of high and new technology and foundation and motive for knowledge-oriented economical development. At the times of knowledge economy, the role and functions of universities will take great changes, and are pushed to the center of the social economy and become the element for economic development. Thus, higher education in Jilin Province has to be strengthened to offer sustainable motive for social development and to form a developmental situation with benign interaction between higher education and social economy.

According to relevant data, overall evaluation on higher education competitiveness in 31 provincial administrative regions in the mainland China indicated, higher education in Beijing, Shanghai and Tianjin were more competitive and Jilin took up the $11^{\text {th }}$, belonging to the fourth category. In the ranking of the overall competitiveness of all provinces, municipal cities and regions in 2008, Jilin occupied a midstream position, ranking the $15^{\text {th }}$. Considering the overall situation, the economic development of Jilin Province was at a medium-and-lower level across the country, and its higher education development level was generally in accordance with its economic development. In the current trend of rapid knowledge and economic development, it is an important approach to realize sustainable development to vigorously develop higher education to enhance the regional competitiveness of Jilin Province and realize benign interaction between economy and education.

\section{Cultural establishment of universities drives urban cultural progress}

Only if a city becomes the locomotive in the regional economic development, can it better drive and radiate the surrounding areas. Furthermore, cultural establishment of a city is gradually becoming the soul and motive for construction of modern cities. Urban culture refers to the ideological and value concepts and the forms of their expression that are created by human being in the process of urban development and that are taken in from the outside, including thoughts, norms and arts, etc. In the contemporary society, a large majority of cities place high emphasis on cultural construction of a city, and cultural elements have played a more and more important role in urban economic and social development. According to practice, first-class cities have to have first-class urban culture as their deposits, because urban culture is not only the cohesive force of the cities and important elements for their overall competitiveness, but more the temperament, strength of character and soul of the cities, and the important footstone and characteristics of the modernization of the cities.

\subsection{University culture is the most advanced component in urban culture}

Competitiveness of a city finally depends on the prosperity of its culture, while prosperity and development of its culture, as well as its basic strength and cultural support are the university resources of local areas. University is the most advanced component of the culture in a city and is a group that has most innovative consciousness. In order to enhance the culture of a city, universities have to be depended, since universities are mostly located in cities, which determines that universities re the cultural elites of the cities where they are located and their culture is the most advanced culture in the cities.

In order to enhance the competitiveness of a city so as to drive regional competitiveness, prosperity and development of culture is the key, and as the messenger for cultural transmission, universities play an irreplaceable role. For the time being, quite a large number of cities have put forward in succession the strategy of "strong city of culture". For instance, Qingdao is a newly emerging city which has a history of only a hundred years or so, and its urban culture is internalized into the concept of Qingdao citizens, condensed to the urban spirit of "credit, harmony, excellent and broadness", and materialized into ocean culture, brand culture, community culture, plaza culture and etiquette culture. In order to transfer urban cultural resources to realistic wealth and revitalize the urban economy with culture, the first thing to do is to enhance the urban cultural level, make its quality and scale attain a new height and enable its power to be stronger.

\subsection{University culture is an important motive to enhance the urban cultural competitiveness}

In interactive relationship exists between university culture and city culture. On one hand, university culture 
reflects the direction of social development and progress and features of the times, gets rid of the stale and takes in the fresh, forms a culture imbued with characteristics of the times, pushes forward development of city culture with its own cultural advantages and plays an important role in enhancing the cultural competitiveness of the city. On the other hand, city culture is penetrated into university culture and pushes forward its development. Especially, the first function of the university culture should be given full play.

University culture is an occasion in which progressive components in regional culture are most concentrated, a sign for the social civilization of the region where it belongs and thus, may push forward generation of city culture. Universities play a foundational role in urban technical innovation system and provide intelligent support and scientific guarantee for urban economic development and social progress.

Excellent scholars in universities not only get a mastery of encyclopedical scientific culture knowledge, but also have particular scientific spirit and humanistic spirit under long-term influences of university culture. On one hand, their activities of scientific research, education and teaching, and writing books and setting up a theory enrich human spiritual culture and humanistic culture. On the other hand, the social activities held by these scholars and their earnest practice of what they advocate bring humanistic spirit and scientific spirit into the society and are carried forward in development and establishment of the city, becoming the component of the city's spirit.

Universities bring quite a lot of qualified talents for social development through the function of educating and teaching. In the final analysis, city culture is the spirit of "human" in the city and modeling of the city culture is ultimately modeling of the human spirit. University is a place that cultivates talents for the society, so education of universities has most direct and profound influences, not only affecting the knowledge level of students, but also affecting their personality quality, ideological consciousness and even behaviors all their life. University students are also constructors of the city, because they make practical contributions to the construction of the city through the social exercise activities of working in community and factories, etc. University graduates stay in the city where their universities are located, go deep into all industries and fields of construction of the city, become higher level citizens of the city and contribute their youth and strength to construction of the city. Through the function of education, universities cultivate generations of talents with independent personality, abundant soul, sensitive creation ability and lofty moral sentiment. After they enter the society, these talents will naturally have a brand of university culture and university spirit, pioneer spirit of the era and set up new national spiritual appearance. Culture depends on "culture of people", so cultivation of new generations will enable the city culture endless and incessant.

Comparatively speaking, Jilin Province is a province with relatively developed higher education. By the end of 2007, there had already altogether been 44 general institutions of higher learning in the province, including 25 undergraduate universities and 19 vocational colleges, and 11 independent colleges that were acknowledged by the Ministry of Education and 20 independently established adult colleges. The gross enrollment ratio of higher education achieved $29.7 \%$ (statistical bulletin of the education business in Jilin Province in 2007), and Jilin is one of the provinces that enter popularization of higher education earlier. Graduates who stay in Jilin Province for work account for a large rate, so we have to give full play toe the positive stimulating role of university culture to cultivate more talents with high quality.

\subsection{To enhance regional cultural competitiveness by depending on university culture}

In the new situation of reform and opening up, higher education has far exceeded narrow fields of "scholastic culture" and "fence culture", and the social functions of the school get further expanded, beginning to play a brand-new social role in modern cities.

To cultivate talents through teaching of multiple forms and multiple levels. Exploring their own potentials and furnishing adult continuing education of multiple levels, multiple disciplines and multiple varieties, universities can not only satisfy learning requirements of a variety of working staff and enable them to upgrade knowledge and improve their business capacity and technical level, but can also satisfy requirements of some people waiting for employment, housewives and retired elderly people, so as to enhance their cultural level and cultural quality and increase their life sentiment, such as, community colleges in US and senior-citizen universities that depend on universities in China. In addition, cultural and arts education enhances and enriches people's mental outlook, makes people's value concepts transfer from sharing of material life to lofty spiritual and value pursuit, which helps to form the social fashion of "respecting knowledge, respecting science and respecting talents",

Cultural resource and information participation and city cultural establishment. On the basis of abundant document literature and particular and advanced equipment, universities resort to their laboratories, computer-assisted audio-visual centers, testing and calculation centers, databases and libraries to offer 
information consulting service that is required by different fields, which is an important aspect for higher education to take part in city cultural establishment. Besides, universities possess lots of scientific research and academic groups to cooperate with municipal administration department of the cities, cultural department, scientific research department and mass organizations, cooperate with such mass communication's media as broadcast and TV, exchanging academic tendency, developing cooperative research, form three-dimensional social education network and promoting establishment and development of city culture.

Quite a large number of cities in the world resort to foundation and advantages of local culture to carry out developmental strategies of city culture, which has made great progress. For example, London carries out the strategy of "metropolis of world cultural diversification", Manchester carries out the "strategy of metropolis of innovation", Barcelona carries out the "strategy of culture-knowledge city", Singapore carries out "the strategic plan of the Renaissance city in Asia", Hong Kong carries out "the plan of a city of infinite originality and city of life", Beijing carries out the "strategy of a city of center for world innovation", and Chengdu and Hangzhou are dedicated to construction of "a city of cultural recreation", which all offer beneficial thoughts for positioning of city culture in Changchun.

At the culture working conference held in Changchun in 2009, the government formally proposed constructing a modern cultural city in Northeast Asia. This is selection and cognition of a city going towards cultural consciousness, which proves that Changchun has already had clear-cut city culture idea. Confirmation of the theme culture of a city has great significance to enhance attraction and influences of a city, strengthen the cultural competitiveness of the city and enhance the cultural competitiveness of Jilin Province. Construction of a modern culture city can't go without universities which is the base for cultivating and expanding modern culture.

\section{Scientific research in universities to strengthen regional innovative ability}

Regional innovative ability refers to the ability that within a certain boundary, the innovation subject elements and non-subject elements that are connected with innovation constitute a sort of network organization, enterprises, universities, independent scientific research institutes, government and intermediary organs constitute innovation nodes, cooperate with each other, integrate resources, re-optimize and re-allocate the resources, define ne types of operational rules so as to enhance the efficacy of resource allocation and output and promote development of urban economy. This sort of regional innovative ability contains several aspects, such as, knowledge, technology, service, system and industry, etc.

"Innovation" with the motive of higher education is the key to "the advantage of backwardness". The advantage of backwardness theory means that, economically underdeveloped countries and regions make full use of superiorities in resources, innovation, opportunities and policies, etc. to obtain optimal economic benefit and higher economic growth speed, realize assimilation with economy of developed countries and regions, and even surpass the economic development level of developed countries and regions and realize great-leap-forward development. The key to build and function the advantage of backwardness is to deem innovation as the soul of the advantage of backwardness. Higher education has positive effects on technological innovation, since potential technological advantages can be transformed to realistic productivity through transfer of scientific achievements and can provide intelligent support for realization of economic catch-up.

Ever since the 50s in the Twentieth century, all countries over the world have universally set up the system of cooperation among industries, universities and research institutes in order to promote the economic development, so cooperative education of universities and enterprises and cooperative scientific research have been rapidly developed. The government of all countries has given high focus on and attached great importance to influences that are brought about by higher education development on the society. For example, such countries as Germany, Japan and France have promulgated relevant policies to promote bi-directional cooperation between universities and the society at the time of rapidly developing higher education, with the aim of making the relationship between higher education and the industries closer. Thus, higher education has gradually become the primary power for social innovation. Interactive development of the higher education and regions in China has started late compared with developed countries. Thus, in the process of detailed implementation, the system and policies have, to some extent, constrained expansion of higher education and regional interactive development, which is unfavorable for improvement of the comprehensive regional competitiveness.

So far as the situation of Jilin Province is concerned, its foundation of higher education is good (a complete range of subjects and disciplines), relatively concentrated higher education resources (28 colleges and universities are set up in Changchun, the provincial capital), and the higher education system is relatively perfect (research-oriented universities, teaching and research-oriented universities and teaching-oriented universities). Based on this precondition, if the universities can give full play and make full use of these resources and adopt 
effective measures to promote development of scientific research of universities and transfer of achievements, then the overall development level of universities will be greatly enhanced in promoting regional development of Jilin Province.

\subsection{Universities strengthen scientific research for industrial development}

Innovation is the reflection of subjective initiative of human being, and excellent scientists and scientific technological talents are the decisive elements of the national or regional innovative activities, while universities are a place where higher education and academic research is conducted, a place where constructors and successors with high quality are cultivated and a place where high-tech talents are fostered. In addition to the function of cultivating talents, another important function of universities in innovation is to research and develop, which is of great significance to enhance the innovative ability of the areas where the universities are located.

Universities have to keep a foothold in the strategic height of the society, especially the development of the economic society, take into consideration the situation of the large agriculture province of Jilin, take a broad view of the major battlefield of the national economy with an innovative thinking and considering the strategic target of the economic and social development in Jilin Province, develop critical and generic technology and apply fundamental research and high and new technology application research in industries, seek for an appropriate position within all fields of the scientific innovation system, strengthen basic, prospective and frontier scientific research, attempt to resolve significant social and economic issues which are related with the overall situation and which are the basis, and maintain sustainable, swift and healthy development of regional social and economic development and cultural development.

\subsection{To set up technological sharing platform depending on universities}

Higher education is the foundation and improvement of comprehensive regional strength is the goal. Organic combination of the two, integration of their advantages and integrative development of the two can enhance the comprehensive regional competitiveness and can also enable higher education to be further developed, coordinating interest relations of all parties involved based on this goal. Nevertheless, in the contemporary interactive cooperation, there is a relatively prominent issue, namely, all the parties involved in the interaction usually come to understand the goal of interactive development from their own perspective and have no coordinated value orientation, which leads to misunderstanding in positioning of respective roles in the interactive cooperation. For instance, as for some scientific projects that have been finished, what universities take more into consideration is the pioneering of discipline construction, what research institutes concentrate on is the consecutiveness of professional research and what enterprises take more consideration is the market risk. Each party independently considers maximization of its interests, which leads to obvious gap in cognition. For example, the attitude of universities at an earlier stage that "fertile water should not flow into the paddy fields of outsiders" has been existing so far to a certain extent. Some universities even mechanically set transfer of achievements and industrialization against teaching and scientific research, which leads to the disadvantages of many research achievements, few transfer of achievements and difficulty in gaining significant economic benefits after transfer and relative separation of knowledge dissemination (education institutes), knowledge discovery (research institutes) and knowledge materialization (enterprises) as well as difficult transfer of scientific achievements. In addition, sometimes, great cultural distinction exists between universities and enterprises, which also leads to inconformity in cognition of the interactive process. University culture advocates free exploration, contention of a hundred schools of thought and all flowers blooming together, scientific research culture advocates preciseness, meticulousness, being practical and realistic and enterprises advocate innovation, speed, competition, cooperation and credit. The cultural distinction between the three is also quite obvious. In the process of interactive cooperation, there might be impediment in exchange and communication as well as coordination and interaction, one of the reasons for which is the service by the government. Although the government service has gained achievement in promoting of higher education and regional interactive development, the strength needs to be intensified in terms of integration of social resources, public service of industries, universities and research institutes, transfer of scientific research achievements and information service, etc. Furthermore, considering the arrangement of the system, system of the government about protection and management of intellectual property in universities is not perfect. So far, laws and regulations about transfer of scientific research achievements still need to be gradually improved. Thus, relevant authority of the government should set up and improve financial and investment mechanism, enhance the interest distribution mechanism in the process of cooperation between universities and enterprises, set up all types of sharing platform, fully mobilize all varieties of available resources and serve for the regional economy. The government should play its multiple roles in leading, service and support and enable all parties involved to cooperate and realize win-win in the process of enhancing regional competitiveness of Jilin Province. 
The government ought to give full play to the fountainhead role of universities and research institutes in urban innovation, encourage universities and independent research institutes to marketize their research findings, promote transfer of research findings and give priority support to those scientific research achievements that are transferred on the spot. The government ought to eliminate institutional and industrial estrangement, set up open technological sharing platform and promote high efficiency utilization of generic technology and information resources. In the meanwhile, the government should encourage and support enterprises and universities to conduct multiple patterns of cooperation among industries, enterprises and research institutes, including research and development institutes, key laboratories or project (technology) centers and joint venture and joint stock cooperative science and technology companies that are constructed together by industrial departments and universities, associations of industries, universities and enterprises that are organized and established together by regions and universities, and technological development associations of such patterns of integration among industries, universities and research institutes, starting out from development of high and new technological industries.

The process of integration is a process of making the best of the both worlds, complementary advantages are exchanged and functions of scientific resources are fully performed. The outcome of integration will necessarily push forward independent and innovative development of enterprises and the cities and promote improvement of technological and innovative capacity of enterprises and innovative capacity of the cities. For example, construction of a science park depending on universities is a benign integration pattern. Science park is a commercial support organization whose primary goal is to incubate and support innovative and rapidly growing scientific enterprises.

For the time being, we altogether have 44 nation-level university science parks. There are several ones that are relatively well-known, such as, South China University of Technology Science Park, and Tsinghua Science Park, etc. In the past few years, Jilin Province has depended on universities to set up Jilin University Science park, Changchun University of Science and Technology Science Park and Siping Hongzui University Science Park. With development for three years, Jilin University Science Park had successfully opened a path of self-improvement, pioneering and innovation and healthy development by the year 2005. It had already had 76 enterprises and institutes, with a total registered capital of 0.46 billion Renminbi Yuan, 180 incubation projects in the science park, 90 transferred scientific findings, among which the key incubation projects "electronic plane-table" and "new type of green bionic non-cohesive cooker" were respectively awarded as "excellent product" in the Shenzhen High-tech Achievements Exchange" in 2004 and 2005 and have gained initial economic benefit and social benefit. It was planned that altogether 300 incubation projects would be completed from the year 2006 to 2010, with an output value of more than 1 billion Renminbi Yuan and a tariff of more than 0.1 billion Renminbi Yuan, and products of over ten enterprises or enterprise groups entered the international market. Jilin University Science Park has become a perfect demonstration model of technological innovation base, incubation base for high and new technological enterprises, base for cultivation of innovative and pioneering talents and demonstration base for combination of industries, universities and research institutes, and has vigorously pushed forward economic development of Jilin Province.

\section{References}

Ding, Peiwei. (2008). Survey on the Times for Cultural Industry of Universities and Regional Economic Development. Fortune World, (9).

Gao, Wenbing, Hao, Shuchen et al. (2008). Review of the Distribution and Coordinated Development of Chinese Higher Education Resources. Higher Education Press, January.

Li, Jianping, Li, Minge, Gao, Yanjing et al. (2010). Report on China's Provincial Economic Competitiveness Development (2008-2009). Social Sciences Academic Press, February.

Research Group of Competitiveness and Evaluation Center, Renmin University of China. (2001). Report on China's International Competitiveness Development. Beijing: China Renmin University Press, June.

Wang, shousong. (2006). On Urban Culture and Urban Cultural Construction. Southern Forum, (3). 